\title{
"PAPEL DA ENFERMEIRA JUNTO A MÃES DE CRIANÇAS HOSPITALIZADAS"
}

\author{
Therezinha A. Gonzaga Ramos* \\ Esther Moraes *
}

RBEn/06

RAMOS, T.A.G. e MORAES, E. - "Papel da enfermeira junto a mäes de crianças hospitalizadas". Rev. Bras. Enf.; DF, 29 : 45-55, 1976.

Acompanhando alunos de Enfermagem Pediátrica em estágio em clínicas infantis, pudemos observar que as mães das crianças hospitalizadas estão sofrendo, e nem sempre encontram a assistência de que necessitam.

A presença da mãe, junto ao filho doente no hospital, tem sido vista como benéfica para a criança. Vários são os estudos que tratam dos prejuízos que a separação dos pais acarreta para a criança - JESSNER (1952), ROBERTSON (1953), ERICKSON (1958), SCHAFFER \& CALLENDER (1959), LANGFORD (1961), MAHAFFY (1965), POST (1966), BRANTETTER (1969), KU N Z M A N (1972), STEPHENS (1973), LISBOA (1973) e VELLOSO (1973). No entanto, autores como BRIGHT (1965) e (1966) e MAHAFF' (1965) atestam que a ansiedade é transmitida de mãe para fillho, sendo que esta não é capaz de perceber $e$ atender adequadamente às necessidades da criança hospitalizada, prejudicando, assim, sua capacidade de relacionamento com o filho e com as outras pessoas do hospital, tornando-se, então, um "problema" para a enfermeira. Um pro- blema que nossas enfermeiras ainda não resolveram; algumas delas, quando indagadas a respeito, responderam-nos que as mães acompanhantes "atrapalham 0 tratamento da criança" e "são um caso sério...".

BRIGHT (1965), estudando a ansiedade dos pais junto à criança hospitalizada, sistematiza passos da assistência de enfermagem à familia: o primeiro refere-se ao reconhecimento das manifestaçōes de ansiedade, caracterizadas por alteraçōes fisiológicas e do comportamento; o segundo trata da identificação das causas da ansiedade, e o terceiro, da redução das fontes de ansiedade para a família.

BRIGHT (1965) aponta como principais fontes de ansiedade dos pais a atmosfera hospitalar estranha, o medo pela responsabilidade da doença do filho, a subordinação da mãe-enfermeira, com conseqüente perda de autoconfiança no cuidado do fillho, e a regressão manifestada pela criança hospitalizada. Indica, conforme a origem da ansiedade, condutas diferentes de assistência de enfermagem e salienta que o melhor meca-

* Docentes da Escola de Enfermagem da USP - São Paulo, SP. 
RAMOS, T.A.G. e MORAES, E. - "Papel da enfermeira junto a mães de crianças hospitalizadas". Rev. Bras. Enf.; DF, $29: 45-55,1976$.

nismo de controle, para a mãe acompanhante, é o envolvimento desta no cuidado do filho. Dá especial ênfase à orientação da mãe pela enfermeira (sobre facilidades do meio ambiente, cuidados $e$ tratamento da criança); demonstra, num registro comentado de uma interação mãe-enfermeira, como esta última pode dar apoio e aumentar a autoconfiança da mãe, estabelecendo um relacionamento caracterizado principalmente pela aceitação da ansiedade da mãe, como fenômeno natural, e pela participação de ambas, no cuidado da criança.

ROY (1968), acreditando que a fonte de segurança da criança é o adequado atendimento, pela mãe, de suas necessidades, utilizou o método que chamou de P. I. P. para integrar as mães no papel que devem assumir nos periodos de visita aos filhos. $O$ método $P$. I. $P$. consiste em a enfermeira agir em três etapas, toda a vez em que se aproxima da mãe visitante: (P) presta atenção ao foco de atenção da mãe; (I) informa-a sobre a situação atual da criança (estado de saúde, exames e tratamentos realizados, mudanças de comportamento, etc.) e (P) permite a participação da mãe nos cuidados à criança. A autora considerou este método um meio útil de ajuda à mãe a agir mais adequadamente nos períodos de visita.

BRIGHT (1966) considera que a ansiedade dos pais torna-se uma barreira para a comunicação e que a ciança doente, percebendo a ansiedade da mãe, luta contra a mesma, consumindo grande parte da energia à recuperação da saúde.

Se a finalidade principal da assistência de enfermagem é auxiliar o doente a recuperar a saúde, a interferência da ansiedade da mãe, captada pela criança, torna-se um obstáculo para a enfermeira.

Motivadas pelo assunto, resolvemos: verificar, mais de perto, qual é o comportamento das maes; analisar a quali- dade da assistência de enfermagem diante das necessidades das mães; e localizar o período da hospitalização da criança em que a mãe, acompanhante ou visitante, necessita de maior atenção da enfermeira.

Embora o estudo limite-se à análise de períodos de relacionamento de uma enfermeira observadora com duas mães, achamos interessante relatar estas experiências.

Chamamos de A a mãe de um menino de 6 anos, internado para correção cirúrgica de criptorquidia e fazer postectomia, e de B a mãe de um menino de 9 anos, internado para correção cirúrgica de criptorquidia. Selecionamos crianças com estado geral e prognóstico bons.

As mães que participaram do estudo t1nham instrução primária completa e socialmente pertenciam às classes sociais média alta, mãe $\mathrm{B}$, e média baixa, mãe $\mathrm{A}$.

As mães permaneceram junto às crianças de modo diferente: a mãe A, durante o horário das visitas, e a mãe B com permissão de passar o dia junto ao filho.

O contacto da observadora com as mães foi iniciado após a rotina da admissão, feita pelo pessoal da clínica.

A observadora conversou com a mãe A, diariamente, no horário das visitas; e o tempo de permanência da observadora na clínica foi de uma hora. No dia da cirurgia a observadora esteve com a mãe pela manhã, enquanto a criança estava na sala de operação, e no momento da chegada à enfermaria.

Os contactos da observadora com a mãe B foram diários, ficando ela à disposição da mãe durante uma hora, pela manhã, e meia hora, à tarde.

O relacionamento da observadora com as mães consistiu em deixá-las falarem livremente, compreender as suas necessidades e dar uma resposta em face da situação apresentada. Durante a permanência da observadora na enfermaria, a duração dos diálogos foi determinada pela necessidade das mães. 
RAMOS, T.A.G. e MORAES, E. - "Papel da enfermeira junto a mães de crianças hospitalizadas". Rev. Bras. Enf.; DF, 29 : 45-55, 1976.

Em seguida a cada interação, a observadora registrou, o mais objetivamente possível, a situação encontrada na enfermaria, isto é, o que fazia a mãe entrevistada imediatamente antes de cada interação, e relatou os diálogos ocorridas entre ambas (Anexo I).

Posteriormente, para podermos analisar as tendências dos comportamentos manifestados e o sentido do relacionamento mãe-enfermeira, agrupamos os comportamentos semelhantes. Os comportamentos das mães foram reunidos em três categorias: atende à criança, ocupase em outras atividades (que não o filho) e solicita a atenção da enfermeira observadora (Anexo II). Os comportamentos da enfermeira foram classificados em oito categorias: explora os conhecimentos da mãe; valoriza o cuidado prestado à criança; observa o relacionamento mãe-filho; informa a mãe; envolve a mãe (A) no cuidado do filho; incentiva a mãe (B) a recrear as crianças da enfermaria; interessa-se pela mãe; e presta atenção ao foco de atenção da mãe (Anexo III).

A conduta "presta atenção ao foco de atenção da mãe" é manifestada em situaçōes em que a observadora ouve e permite que a mãe fale livremente; esta. conduta não é apresentada no Anexo III, porque corresponde às situações em que as mães dirigiram-se à enfermeira observadora para expor e comunicar alguma preocupação (comportamento que nós classificamos como "solicita atenção da enfermeira" - ver Anexo II).

Vamos demonstrar, no quadro I, como as mães A e B comportaram-se durante o periodo em que a enfermeira observadora esteve à disposição delas $(6,5$ horas: para a mãe A e 9,5 horas para a mãe B).

QUADRO I

Comportamento das mães A e B

\begin{tabular}{|c|c|c|c|c|c|c|}
\hline \multirow[t]{2}{*}{$\begin{array}{c}\text { DIAS } \\
\text { DE } \\
\text { OBSERVAÇAO }\end{array}$} & \multicolumn{2}{|c|}{$\begin{array}{l}\text { ATENDE O } \\
\text { FILHO }\end{array}$} & \multicolumn{2}{|c|}{$\begin{array}{l}\text { OCUPA-SE EM } \\
\text { OUTRAS ATIVI- } \\
\text { DADES. }\end{array}$} & \multicolumn{2}{|c|}{$\begin{array}{r}\text { SOLICITA A } \\
\text { ATENÇAO DA } \\
\text { ENFERMEIRA }\end{array}$} \\
\hline & A & B & A & B & $\mathbf{A}$ & B \\
\hline 1 & - & 1 & - & 1 & 1 & 1 \\
\hline 2 & 1 & - & - & 1 & 1 & 16 \\
\hline 3 & 2 & - & - & - & 2 & 8 \\
\hline 4 & - & - & - & 1 & 1 & - \\
\hline 5 & $4^{*}$ & 2 & - & 2 & 2 & - \\
\hline 6 & 一** & 2 & 一 & 1 & - & - \\
\hline 7 & 1 & - & - & - & - & $5^{* * *}$ \\
\hline TOTAL & 8 & 5 & - & 6 & 7 & 30 \\
\hline
\end{tabular}

A mãe $\mathrm{A}$ utilizou mais o periodo de visita para dar atenção ao filho do que para solicitar a atenção da enfermeira; a maior freqüência de atendimento do filho ocorreu na situação de pós-operató- rio imediato; esta mãe não se ocupou de outras atividades; e a sua média de solicitação de atenção da enfermeira foi de 1,07 vezes por hora.

A mãe $B$, que passou o dia todo em. 
RAMOS, T.A.G. e MORAES, E. - "Papel da enfermeira junto a mães de crianças hospitalizadas". Rev. Bras. Enf.; DF, 29 : 45-55, 1976.

companhia da criança, solicita a atenção da enfermeira cinco vezes mais do que se ocupa de outras atividades, e seis vezes mais do que cuida do filho; a média de solicitação de atenção da enfermeira foi de 3,15 vezes por hora; esta solicitação ocorreu, principalmente, em três dias: véspera da cirurgia, dia de cirurgia, e no 7.0 dia de observação, quando a mãe imaginou que o filho apresentava $38 .^{\circ} \mathrm{C}$ de temperatura.

Se atentarmos para a qualidade dos comportamentos manifestados pelas mães, em seis e sete dias de relacionamento, poderemos contatar, no Anexo II, que a mãe $A$ aproveita 0 período de visita ao filho para: atender às necessidades da criança (dando carinho, brincando, educando-o, dando apoio psicológico e cooperando no cuidado pós-operatório), e solicitar a atenção da enfermeira, a fim de manifestar suas preocupaçōes relativas aos filhos e demonstrar sua satisfação em poder acompanhar o filho no pós-operatório imediato. Pareceram-nos adequados os comentá- rios da mãe A, quando solicitada a atenção da enfermeira.

Quanto à mãe B, seu atendimento ao filho caracteriza-se por recreação e compra de medicamento em falta no hospital.

O comportamento de "ocupar-se em outras atividades" só foi apresentado pela mãe $B$, o que é explicável, uma vez que sua permanência no hospital foi muito maior que a da mãe $A$.

Em relação ao comportamento "solicita atenção da enfermeira" verifica-se, no Anexo II, que a mãe $B$ demonstra necessidade de: avaliar e comentar o estado de saúde dos fillhos e o seu próprio; comentar o ambiente hospitalar estranho; orientar-se sobre a cirurgia do filho; pedir apoio da enfermeira; expor suas preocupações, queixas e dúvidas; e desabafar.

Nos quadros II e III apresentamos a distribuição de freqüência do tipo de conduta da enfermeira, em relação às mães A e B observada em seis e sete dias de assistência, respectivamente.

QUADRO II

Conduta da enfermeira junto à mãe $A$.

\begin{tabular}{|c|c|c|c|c|c|c|c|c|}
\hline $\begin{array}{c}\text { TIPOS } \\
\text { DE } \\
\text { CONDUTA }\end{array}$ & 1 & DIAS & $\mathrm{DE}$ & AS: & STEN & $\begin{array}{l}\text { CIA } \\
6^{* *}\end{array}$ & 7 & TOTAL \\
\hline $\begin{array}{l}\text { EXPLORA CONHECIMENTOS } \\
\text { PRESTA ATENÇAO AO FOCO }\end{array}$ & 2 & - & - & - & - & - & - & 2 \\
\hline $\begin{array}{l}\text { DE ATENÇAO DA MAE } \\
\text { VALORIZA O CUIDADO DA }\end{array}$ & 1 & 1 & 2 & 1 & 2 & - & 一 & 7 \\
\hline $\begin{array}{l}\text { MAE } \\
\text { OBSERVA O RELACIONA- }\end{array}$ & - & 1 & 2 & - & 1 & - & - & 4 \\
\hline MENTO MAE-FILHO & - & 1 & 1 & 一 & - & - & - & 2 \\
\hline $\begin{array}{l}\text { INFORMA A MAE } \\
\text { ENVOLVE A MAE NO }\end{array}$ & 1 & 1 & - & - & 3 & - & 一 & 5 \\
\hline CUIDADO DO FILHO & - & - & - & - & 3 & - & - & 3 \\
\hline INTERESSA-SE PELA MAE & - & - & 一 & 1 & 1 & - & 1 & 3 \\
\hline TOTAL & 4 & 4 & 5 & 2 & 10 & - & 1 & 26 \\
\hline
\end{tabular}


JRAMOS, T.A.G. e MORAES, E. - "Papel da enfermeira junto a mães de crianças hospitalizadas". Rev. Bras. Enf.; DF, 29 : 45-55, 1976.

QUADRO III

Conduta da enfermeira junto à mãe B.

\begin{tabular}{|c|c|c|c|c|c|c|c|c|}
\hline $\begin{array}{l}\text { TIPOS } \\
\text { DE }\end{array}$ & & & & AS & SIST & NCIA & & \\
\hline CONDUTA & 1 & 2 & $3 *$ & $4^{* *}$ & 5 & 6 & $7 * * *$ & TOTAL \\
\hline $\begin{array}{l}\text { EXPLORA CONHECIMENTOS } \\
\text { PRESTA ATENÇAO AO FOCO }\end{array}$ & 1 & 一 & - & - & - & - & - & 1 \\
\hline $\begin{array}{l}\text { DE ATENÇAOO DA MAE } \\
\text { VALORIZA O CUIDADO DA }\end{array}$ & 1 & 16 & 8 & - & 一 & - & 5 & 30 \\
\hline MAE & - & 1 & 1 & - & - & - & 1 & 3 \\
\hline $\begin{array}{l}\text { INFORMA A MAE } \\
\text { INCENTIVA A MAE A RE- } \\
\text { CREAR AS CRIANÇAS DA }\end{array}$ & - & 3 & 1 & - & - & 一 & 1 & 5 \\
\hline ENFERMARIA & - & - & - & - & 2 & 1 & - & 3 \\
\hline INTERESSA-SE PELA MAE & 一 & 2 & 4 & 1 & 一 & - & - & 7 \\
\hline TOTAL & 2 & 22 & 14 & 1 & 2 & 1 & 7 & 49 \\
\hline
\end{tabular}

* Dia da operação

* Está presente só no horário da visita

** A mãe B imaginou que a criança apresentou $38.0 \mathrm{C}$ de temperatura

Observando-se o quadro II, verifica:se que as condutas mais freqüentes da enfermeira junto à mãe $A$ foram: prestar atenção ao foco de atenção da mãe (7), informar a mãe (5) e valorizar o cuidado prestado ao filho (4). A média de assistência de enfermagem prestada foi de 4 cuidados por hora. A enfermeira observadora deu maior assistência à mãe no dia da cirurgia da criança, assistência esta caracterizada por informar a mãe (3), envolvê-la no cuidado à criança (3), prestar atenção ao foco de atenção ao foco de atenção da mãe (30), ela, numa média de um cuidado a cada nove minutos.

A conduta da enfermeira junto à mãe B foi predominantemente a de prestar atenção ao foco de atenção da mãe (30), interessar-se por ela (7), e informá-la (5). A enfermeira dá maior assistência na véspera da cirurgia (22), no dia da operação (14) e quando a mãe imagina que a criança apresentou $38 .^{\circ} \mathrm{C}$ de temperatura. A média de assistência de en- fermagem prestada à mãe B foi de 5,15 cuidados por hora, demonstrando certa semelhança ao que ocorreu com a mãe $A$.

Observando o Anexo III, onde foram agrupadas as condutas da enfermeira observadora, verifica-se que a intenção do relacionamento por parte da enfermeira gira em torno do controle da ansiedade da mãe, manifesta ou não. As condutas da observadora, apesar de agrupadas em oito categorias, podem ser compreendidas como tendo quatro objetivos: prevenir a ansiedade da mãe (explora os conhecimentos da mãe e informa); permitir que ela exteriorize as causas de sua ansiedade (presta atenção ao foco de atenção da mãe e interessase por ela); e aumentar a segurança ou autoconfiança da mãe (envolvendo-a no cuidado do filho e em outras atividades na enfermaria, e valorizando os cuidados por ela prestados à criança).

A conduta "observa o relacionamento mãe-filho", que ocorreu somente em relação à mãe $A$, tem o sentido de a en- 
RAMOS, T.A.G. e MORAES, E. - "Papel da enfermeira junto a mães de crianças hospitalizadas". Rev. Bras Enf.; DF, 29 : 45-55, 1976.

fermeira verificar a adequação deste relacionamento; é sempre interessante reconhecermos as mães aceitadoras. rejeitadoras e superprotetoras, JERSIID (1966).

As conclusões de nosso trabalho, restritas à análise do relacionamento da enfermeira observadora com duas mães, uma visitante e a outra acompanhante, são de que:

as mães por nós assistidas precisavam de ajuda da enfermeira para lidarem com a sua ansiedade: as duas mães, apesar de terem agido diferentemente, demonstraram ter necessidade da atenção da enfermeira (embora uma das mães tenha prestado mais cuidado ao filho do que solicitado a atenção da enfermeira);

\section{REFERENCIAS}

BLOM, G.E. - The reactions of hospitalized children to illness. Pedriatrics, 22: 590-600, 1958.

BRANSTWTIER, E. - The young child's respouse to hospitalization: separation anxiety or lack of mothering care? Amer. J. Public. Health, 59: 9197, 1969.

BRIGHT, F. - The pediatric nurse and parental anxiety. Nurs. Forom, 4: 3047, 1965.

BRIGHT, F. - Parental anxiety - a barrier to comunication. In: AMERICAN NURSE'S ASSOCIATION - ANA CLINICAL SESSIONS: 1966, New York, Appleton-Century-Crofts, |1968| p. 12-19.

ERICKSON, F. - Reactions of children to hospital experience. Nurs. Outlook, 6: 501-504, 1958.

JHRSIID, A.T. - Psicologia da criança. 5. ${ }^{2}$ ed., Belo Horizonte, Itatiaia, 1986. p. 143-170.

JESSNER, L. et al. - Emotional implications of tonsillectomy and adenoidectomv on children. Psychoanal. Stud. Child., 7: 126-129, 1952.

EONZMAN, L. - Bome factors influencing a young child's mastery of hospitalition. Nurs. Clin of North Amer., 7: 13-26, 1972.

IANGFORD, W.S. - The child in the pediatric hospital: adaptation to lll- o cuidado principal prestado às mães foi o de ouvi-las, o segundo, para a mãe $A$, fol informá-la, e, para a mãe $B$, interessar-se por ela;

o período em que a enfermeira prestou maior assistência às mães, correspondeu à véspera e ao dia da cirurgia das crianças.

Acrescentamos que as duas mães manifestaram prazer em serem ouvidas, e os dois meninos mantiveram-se calmos no pós-operatório, que ocorreu sem anormalidades.

Com essas observaçōes, convidamos as enfermeiras que trabalham em pediatria, a refletirem sobre a possibilidade de receberem e assistirem à mãe visitante ou acompanhante, em benefício dela e da criança.

\section{BIBLIOGRAFICAS}

ness and hospitalization. Amer. J. Orthopsychiat., 31: 667-684, 1961.

LISBOA, A.M.J. - Programa de hospitalizaçăo conjunta măe-filho. Jornal de Pediatria, 38: 191-194, 1973.

MAHAFFY, P.R. - The effects of hospitalization on children admitted for tonsillectomy and adenoidectomy. Nurs. Res., 14: 12-19, 1965.

PLANK, E.N. - Abandonment: deepest fear of hospitalized children. Hosp. Top. 43: 93-96, 1965.

POST, S. - Hospitalization of children under five. Canad. Nurse, 62(7): 3437, 1966.

ROBERTSON, J. - Some responses of young children to loss of maternal care. Nurs. Times, 49: 382-386, 1953.

ROY, S.M.C. - Role cues and mothers of hospitalized children. In: AMERICAN NURSE'S ASSOCIATION - ANA CLINICAL SESSIONA: 1968: New York, Appleton-Century Crofts, |1968| p. 199-206.

SCRAFFER, H.R. \& CAWWENDER, W M Psychologic effects of hospitalization in infancy. Pediatrics, 23: 528-539, 1959.

VWLIOSO, N.A. - Influência da assistência de enfermagem no ajustamento de crianças admitidas no dia ou na véspera da operaçăo. Rev. Esc. Enl. da USP, 7 (1) $14-15,1973$. 


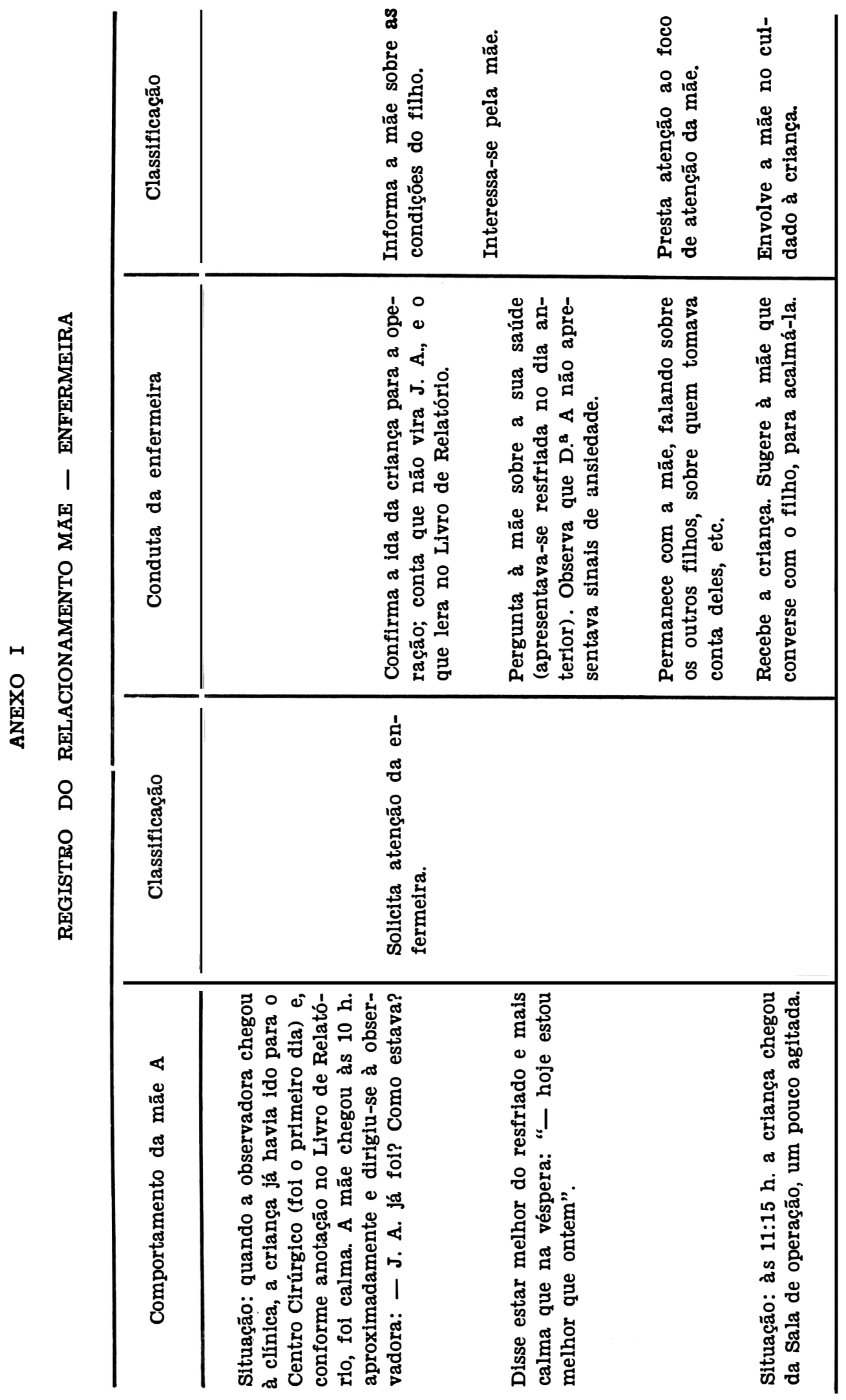




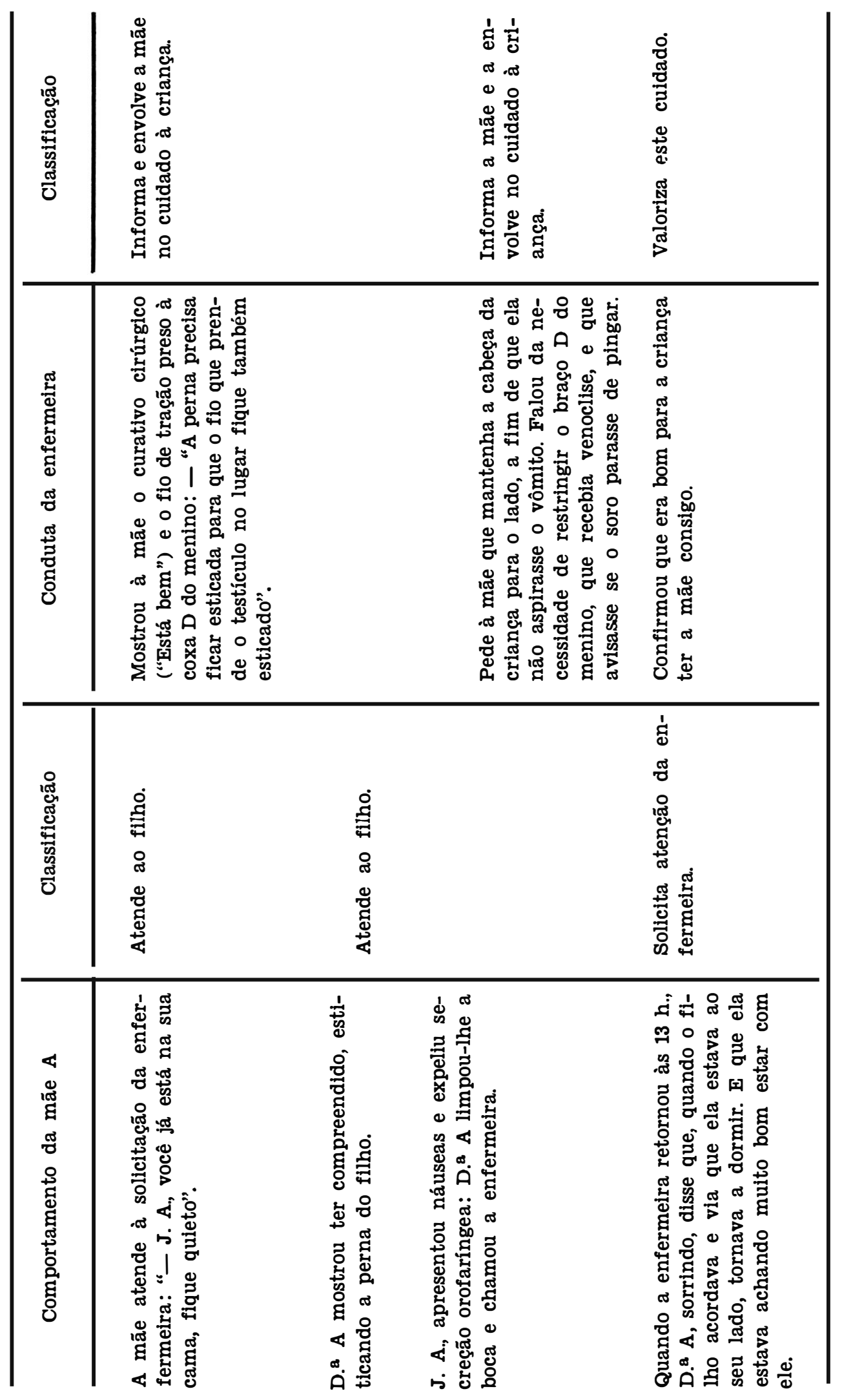


RAMOS, T.A.G. e MORAES, E. - "Papel da enfermeira junto a mães de crianças hospitalizadas". Rev. Bras. Enf.; DF, 29 : 45-55, 1976.

\section{ANEXO II}

\section{COMPORTAMENTO DA MAE A.}

Atendendo à criança.

Beijou o filho e repreendeu-o quando soube das suas travessuras (jogar pedaços de reboco nas pessoas que passavam na rua).

Abraçou e beijou o filho

Auxiliou o filho na construção de casinhas com blocos de madeira.

$\mathrm{Na}$ situação de pós-operatório imediato da criança, acalmou o filho, dizendo: "Você já está na sua cama, fique quieto".

A mãe, compreendendo a orientação da enfermeira, isto é, a necessidade de manter esticado o fio de tração do escroto preso na coxa direita da criança, colaborou na assistência.

Limpou a boca do filho e chamou a observadora quando a criança apresentou náusea e expeliu secreção orofaríngea.

No $5 .^{\circ}$ dia de hospitalização, a mãe, prevendo não poder visitar a criança no dia seguinte, deixou uma fotografia sua e do marido para que o filho olhasse quando sentisse saudades deles. (A criança disse: "minha mãe trouxe a fotografia para que eu não sentisse saudades de casa".)

A mãe A foi observada brincando com o filho acamado.

Solicitando atenção da enfermeira

- "Acho que à noite o J. A. val estranhar um pouco".

Comentou que pensou no filho a noite toda, e que era a primeira vez que ficava longe dele.

- "Eu sei que ele está bem e que precisa ser operado, mas sinto muito falta dele, principalmente à noite".

Comentou que era muito apegada aos filhos, e contou o tratamento de febre reumática do J. A.

Falou dos outros filhos, e de quem ajudava a tomar conta deles em casa.

Perguntou à observadora, no dia da operação: - "J. A. já foi? Como estava?"
Contou que o filho se acalmava quando a via ao seu lado, e que achava bom estar ao lado dele.

COMPORTAMENTO DA MAE B.

Atendendo à criança.

Incentivou o filho jogar dominó.

Pediu emprestadas as tintas da observadora, pois o filho queria pintar como as outras crianças.

Fol encontrada brincando com o filho acamado.

Pediu outra vez as tintas para o filho brincar.

Foi comprar um medicamento em falta no hospital.

Ocupando-se em outras atividades.

No dia da admissão do filho, ofereceu água para uma outra criança.

Consolou uma criança recém-admitida que estava chorando.

Brincou com as crianças da enfermaria (duas vezes).

Conversou com os familiares que visitavam o filho.

Orientou e ajudou as crianças da enfermaria a limparem as mesinhas sujas de tinta.

Solicitando atenção da enfermeira

Referiu-se ao filho: "Hoje ele está um pouco quieto, mas eu lhe disse que amanhã estará melhor e que há muitas crianças aqui".

Comentou: "Hoje ele está bem maís animado. Bem que eu lhe falei. Chegou um menino quase da idade dele e o $R$. está contente por isso".

- "Eu é que passei mal - tive uma crise asmática nervosa. Controlei-me o dia todo ontem, mas quando cheguei em casa não aguentei mais".

- "Eu estava muito nervosa; nunca nenhum filho meu ficou internado. No hospital é tudo diferente, a gente não conhece o ambiente. $O$ meu filho é tímido e está nervoso".

Comentou que o marido queria que o filho fosse para um hospital que permi- 
RAMOS, T.A.G. e MORAES, E. - "Papel da enfermeira junto a mães de crianças hospitalizadas". Rev. Bras. Ent.; DF, 29 : 45-55, 1976.

tisse acompanhante, mas ela preferiu este hospital por achá-lo melhor.

Falou do segundo filho, que tinha um sopro cardíaco e precisava fazer amigdalectomia: - "Será que não há perigo na operação?"

- “O R. val ficar muito tempo aqui?"

- "Como val ser o corte do R.? Há tantas crianças aqui com cortes feios!..." - "Ele val ficar como? Eu não sei..."

- "E, o médico me falou que o $R$. val ficar em repouso; falou também que daqui a uns dias val poder viajar em férias com os irmãos."

- "A Dona Enfermeira falou alguma coisa de mim para a senhora? Parece que ela não quer que eu fique aqui".

Despediu-se da enfermeira: - 'Muito obrigada. Foi bom falar com a senhora - eu desabafei".

Falando com o médico: - "Meu filho é muito nervoso. O senhor precisa ver como ficou quando a moça veio retirar o sangue dele para exame. Levou mais de um hora para voltar-lhe a cor".

- "Estou com uma dor de cabeça terrível. Deve ser por causa dos remédios que tomei ontem".

- "Eu não fico sossegada em casa sabendo o R. aqui". - "O médico achou o R. muito nervoso".

- "Eu sel que a enfermeira não quer que eu fique aqui para o bem do meu filho. Mas eu é que não posso ficar em casa. Eu cuido dos meus filhos feito uma doida".

Despediu-se da enfermeira: "- Até amanhã e muito obrigada. um calmante para mim. bom conversar com a senhora".

- 'O R. subiu para a sala de operação. Eu saí um pouco e, quando voltei, ele Já havio ido".

- "Eu estou quase morta".

- "A minha sogra não queria que eu viesse, mas eu vinha de qualquer jeito. Ela não queria que eu contasse para o $R$. que ele Iria ser operado."

- "Eu fico nervosa sem saber se estou certa. Se eu tivesse mais estudo... Eu falo sempre a verdade para meus filhos. o que a senhora acha?'

Comentou os erros da sua educação como filha única; uma educação rígida e com pouca orientação. - "Eu não sel. Eu faço o que posso.. - "Enquanto não passar a operação do R. eu não sossego. Acho que só amanhã eu vou ficar tranqüila. Amanhã já não haverá mais perigo." - "Nunca fui operada, nem ninguém de minha casa. Acho que vou aprender."

- "Se eu não estiver boa, é a minha sogra que val ficar com o $R$. à noite."

- 'Está tudo bem, mas eu fiquel muito preocupada ontem. $O R$. teve febre de quase $38 .^{\circ} \mathrm{C}$. Eu só sosseguel quando telefonel para o médico e ele disse que não era nada."

- "O R. emagreceu; também, ele não come! Eu acho que é por causa disto que o intestino dele não funcionou e, além do mais, ele ficou muito tempo deitado." - "Ele levantou hoje, a senhora viu?" - "A senhora sabe que os meus nervos me abalaram toda? A minha menstrução só velo um dia e parou."

- "Graças a Deus o R. está bem" - disse D. ${ }^{a} \mathrm{~B}$.

- "No dia 28, o meu outro filho val operar a garganta aqui no $6 .^{\circ}$ andar. Mas garganta é um dia só, não é? Eu já estou esgotada."

\section{ANEXO III}

\section{CONDUTA DA OBSERVADORA JUNTO}

\section{A MAE A.}

\section{EXPLORA OS CONHECIMENTOS}

- "Qual a cirurgia proposta para a criança?"

Perguntou à mãe se a criança sabia que iria ficar no hospital e se sabia o tratamento que receberia.

\section{VALORIZA O CUIDADO MATERNO PRESTADO A CRIANÇA}

Comentou que era melhor para a criança que fosse operada antes de entrar para escola. 
RAMOS, T.A.G. e MORAES, E. - "Papel da enfermeira junto a mães de crianças hospitalizadas". Rev. Bras. Enf.; DF, 29 : 45-55, 1976.

Valorizou o cuidado da mãe durante o período em que a criança apresentou febre reumática.

Valorizou o comportamento da mãe brincando com o filho.

Valorizou o comportamento da mãe, que acalmava o filho quando este recuperava a consciência.

\section{OBSERVA O RELACIONAMENTO MAE-FILHO}

Uma situação em que beija o filho e o repreende por travessuras.

Outra situação, em que beijava e abraçava o filho.

\section{INFORMA A MAE}

Que à noite também havia pessoal de enfermagem na clínica.

Que a data da cirurgia estava marcada.

As condiçōes da criança ao ir para a sala de cirurgia.

As condições da incisão cirúrgica.

Explicou a necessidade de manter restringido o braço da criança que está recebendo venoclise.

\section{ENVOLVE A MAE NO CUIDADO DO FILHO}

Pediu à mãe que acalmasse a criança. Pediu à mãe para conservar esticada a perna com o fio de tração do escroto.

Orientou-a para que mantivesse a cabeça da criança de lado, a fim de impedir a aspiração de vômito.

\section{INTERESSA-SE PELA MAE}

Indagou sobre o estado de saúde da mãe.

Perguntou se estava melhor.

CONDUTA DA OBSERVADORA JUNTO A MAE B.

\section{EXPLORA OS CONHECIMENTOS}

— "Por que fulano está internado?"

\section{VALORIZA O CUIDADO DA MAE}

- "A senhora fez bem em controlar-se na frente do R."

- "A senhora fez muito bem em dizer a verdade ao seu filho."

Valorizou o cuidado da mãe em ter trazido a criança para ser operada logo após as festas de fim de ano.

\section{INCENTIVA A MAE A RECREAR AS CRIANÇAS DA ENFERMARIA}

Orientou a mãe a participar das atividades das crianças (três vezes).

\section{INTERESSA-SE PELA MAE}

- "Por que a senhora passou mal o dia de ontem?"

- "Hoje a senhora está melhor?"

Perguntou como a mãe está passando: - "A senhora está melhor hoje?"

- "A senhora não está se sentindo bem?"

Cumprimentou, e perguntou: - "Como vai a senhora?"

- "Como está, Dona Fulana?"

\section{INFORMA A MAE}

Aconselhou a mãe a contar ao Otorrinolaringologista sobre o sopro cardíaco do outro filho antes da cirurgia das amigdalas.

Informou-se sobre o período provável de hospitalização de crianças amigdaletomizadas.

Orientou-a sobre o local da incisão de R., e explicou que as outras crianças da enfermaria apresentavam prohlemas diferentes. dias."

- "O R. vai ficar em repouso alguns

Informou a mãe sobre as condições prováveis da criança, no pós-operatório imediato. 